\title{
The role of nutrition in tackling dental caries
}

\author{
Nishat Zafar ${ }^{*}$, Ashiq $\mathrm{Ali}^{3}$, Shanzay Imtiaz², Muhammad Yasir Afzal2, \\ Usman Nazir ${ }^{2}$, Muhammad Sikandar ${ }^{4}$, Sana Ghafar ${ }^{1}$, Saba Siddiq ${ }^{4}$, \\ Abdullah Zafar ${ }^{1}$, Fariha Mazhar ${ }^{1}$ and Muhammad Sarwar ${ }^{1}$ \\ 1. Institute of Microbiology, Faculty of Veterinary Science, University of Agriculture Faisalabad, (38000)-Pakistan \\ 2. Department of Microbiology, Government College University, Faisalabad, (38000)-Pakistan \\ 3. Department of Pathology, University of Agriculture, Faisalabad, (38000)-Pakistan \\ 4. Department of Zoology wildlife and fisheries, University of Agriculture, Faisalabad, (38000)-Pakistan \\ *Corresponding author's email: nishat_zafar@yahoo.com
}

Citation

Nishat Zafar, Ashiq Ali, Shanzay Imtiaz, Muhammad Yasir Afzal, Usman Nazir, Muhammad Sikandar, Sana Ghafar, Saba Siddiq, Abdullah Zafar, Fariha Mazhar and Muhammad Sarwar. The role of nutrition in tackling dental caries. Pure and Applied Biology. Vol. 9, Issue 4, pp2233-2249. http://dx.doi.org/10.19045/bspab.2020.90239

\begin{tabular}{llll}
\hline \hline Received: 02/03/2020 & Revised: 04/06/2020 & Accepted: 26/06/2020 & Online First: 07/07/2020 \\
\hline
\end{tabular}

\section{Abstract}

Nutrition provides life to cells, their components, and organisms. It is the adequate stipulation of substances like various minerals, fiber, vitamins, water, and some other necessary food components. Malnutrition may lead to the oral cavity and cause oral disease that can cause by many factors like changing in tissue homeostasis, decreased tissue repairment, and reduced resistance to microbial load. Low intake of food, deficiency of nutrients, and improper consumption of nutrients in the everyday diet promote oral and dental problems in individuals. It can lead to many health issues and cause many diseases. Fruits and vegetables contain many nutrients that promote good health and fight against many diseases, but the $\mathrm{pH}$ of many fruits can be acidic, and it promotes tooth decay. It shows that the simple fruit lowers less $\mathrm{pH}$ of saliva as juxtapose to processed juices due to the presence of artificial sugars. Simple fruit contains more nutrients than juices. But fresh juice contains nutrients that accept fiber content and less deduction of other nutrients than in processed juice. Fresh juices lower the $\mathrm{pH}$ and help to destroy microorganisms. Daily consumption of processed juice can cause dental caries which lead to loss of teeth in later ages. Oral health is most important for the rest of the body; any oral diseases can lead to many other diseases in the body. The $\mathrm{pH}$ of saliva has great importance in an individual's life, as the $\mathrm{pH}$ decreases it increases the chance of production of microorganisms. Microorganisms are the key role in developing dental caries. Acidic foods decrease the $\mathrm{pH}$ and cause more microorganisms.

Keywords: Diet; Nutrition; Oral hygiene; Saliva

\section{Introduction}

Nutrition is the study of food, how it reacts, and affects the body. Nutrition provides life to cells, their components, and organisms. It is the adequate stipulation of substances like various minerals, fiber, vitamins, water, and some other necessary food components. Many common health issues can prevent or relieved with good nutrition [1]. Diet is the volume or number of commodities of foods which ingested by human being every day and have a great impact on the human body 
[2]. Fruits and vegetables have great importance in human life as it helps in many metabolic processes and help in fighting against many chronic diseases. According to the world health organization (WHO), the minimum consumption of $400 \mathrm{~g}$ of vegetables and fruits daily intake helps in fighting many chronic diseases [3]. For example, type 2 diabetes [4] heart diseases [5] dementia [6], glaucoma [7], cancer [8], hypertension [9], and many other diseases. Fruits and vegetables help in improving the multimorbidity [10].

Diet in the subject of nutrition can be called the sum of all foods consumed by an individual daily. Diet has a great effect on the metabolic processes of the body. Diet and oral health come side by side especially in the matter of saliva. Saliva is the watery material secreted by the salivary gland present in the mouth. The saliva of human beings is composed of $99.5 \%$ water and the other $0.5 \%$ is composed of mucus, glycoprotein, electrolytes, antimicrobial agents, and enzymes. An approximately healthy person can produce about 0.75 -1.5-liter saliva per day but the amount becomes almost zero in sleeping conditions [2]. Nutrition is a potent constituent of oral health. There is a ceaseless synergy between nutrition and the state of the oral cavity in the health and problems associated with them [11]. Malnutrition may lead to the oral cavity and cause oral disease that can cause by many factors like changing in tissue homeostasis, decreased tissue repairment, and reduced resistance to microbial load [12]. There's a diverse relationship between nutrition and oral health, just like that oral health has a great impact on nutrition, and nutrition also affects oral health [13].

Nutritional status and oral health have greatly impacted each other [24]. Improper food intake and lack of nutrients in the diet can increase the chance of oral health problems [14]. If food is not properly chewed than it can cause malnutrition at any age of life while proper chewing can help in proper absorption of nutrients and improve the health of an individual [15]. Dental health problems in childhood can cause problems of dental cavities in future life [16]. Children with dental problems can disturb their intellectual growth interfering with nutrition, concentration in school, and their comfort level but motivational interviewing can help in improving dental health [17]. Oral caries is several factor sickness and a few elements have been related to dental caries, including oral cleanliness, fluoride revelation, access to oral care, bottle encouraging, and admission of sustenance or refreshments that are high in sucrose and starches [18]. The presence of a high level of DMFT (number of decayed, missing, and filled teeth) shows that an individual's regular intake of food consists of a high level of sugary foods [19].

\section{Oral diseases}

Oral hygiene and nutritional status have a sizeable influence on each other [24]. Low intake of food, deficiency of nutrients, and improper consumption of nutrients in the everyday diet promote oral and dental problems in individuals. If a person is taking proper diet and nutrients in the daily diet it helps in improving the health and prevention of many diseases but if he does not chew the food properly then food does not provide proper nourishment and can cause the problem in digestion and absorption in the body. It can lead to many health issues and cause many diseases [41].

Oral cavities are formed when the $\mathrm{pH}$ of saliva goes to acidic medium and it promotes the growth of certain bacteria but they are some bacterial species who promote the rose in $\mathrm{pH}$ and help them to goes in alkali medium like lactobacillus, Streptococcus mitis, actinomycetes, spirochetes, Streptococcus parasanguinis, and Streptococcus gordonii. Free arginine which is not bound to any peptides metabolizes these bacteria with the 
help of arginine deaminase and converts them to ornithine, carbon dioxide, and ammonia. The diet having more arginine encourages the production of these microbes [42] and helps in protecting the oral cavity by increasing in $\mathrm{pH}$ of saliva, fasten the internal tubules of the tooth, and revitalize the dentine with the help of minerals and vitamins like vitamin $D$, calcium, vitamin $K$ and magnesium [43]. When alkaline metabolites are formed then it helps in removing the tooth decay in their premature period [44]. Type of diet intake, the amount and type of bacteria present on the surface of teeth, and the amount of saliva production is greatly associated with oral cavities. When the $\mathrm{pH}$ of saliva goes to acidic medium and growth of those bacteria which cause dental cavities like lactobacillus caesi and streptococcus mutants assist the development of oral cavities. Additionally, more drop in $\mathrm{pH}$ level can cause demineralization of the surface of teeth. The $\mathrm{pH}$ of plaque has a rudimentary character instability of biofilm on the exterior part of the tooth [45].

Oral haleness is the window into the fitness of the body. It is a fundamental part of health because it is considered a door to numerous diseases of the body. Any diseases in the mouth (sores, facial pain, bacterial or viral infection, throat pain, and cancer) can cause problems in chewing which can lead to further health problems. According to the World Health Organization (WHO), three main oral diseases are dental cavities, periodontal disease, and mouth cancer. School going children have the chance of cavities around $60-90 \%$. Periodontal disease can lead to tooth loss in middle age (35-44 years), around $15-20 \%$. People who give less attention to their oral health can lead to oral cancer [46]. Oral cavities help in the diagnosis of diseases and their treatment. It also acts as an indicator of health.

In the case of oral health, nutrition does not affect only the issues related to dental health but also has an impact on overall general body health. Gum disease, the problem in mucus membranes, disruption in teeth, dental caries, and problem in salivary gland they are infectious and interpret the integrity of oral health [47]. Dietary intake is a determining factor for the oral tissues to which bacteria bind to substrates (i.e. epithelium, collagen, bone, teeth), as well as saliva. Common oral diseases are periodontal and dental cavities and they lead to tooth pain in childhood and may lead to tooth loss during adulthood. These diseases are common in developing countries due to a lack of oral health care. Many cases also register daily in industrialized states of countries. In European countries, these diseases seem to be reduced in fresh years due to health care. After different types of studies which include longitudinal and many observational studies show that different possible elements lead to dental cavities, it includes clinical factors, behavioral factors, and nutritional factors. Behavioral components include the utilization of products containing fluorine daily, the number of brushing daily, frequency of going to the dentist. Consistency and frequency of utilization of dental carried causing foods [48]. Within these possible factors, nutritional and behavioral components can be faultless with small effort, and then these practices can be habitual with time and small attempts. If these practices develop in early ages and continue in later ages foremost towards good oral health. The study includes $44.5 \%$ males and $55.6 \%$ females. The result shows that $93 \%$ brushed their teeth daily but $36.2 \%$ do not use fluoridated toothpaste. Almost $95 \%$ had 4-6 teeth containing plaque [49].

\section{Species in dental caries}

Miller's theory was widely accepted that the number of bacteria present in the mouth like Streptococcus mutans, Streptococcus sorbinus, Lactobacillus spp. and Actinomyces spp. were responsible for the 
formation of acids from the process of decomposition of carbohydrate. Then these acids promote the dissolving of calcium phosphate which was present in the enamel of teeth. Lowered salivary $\mathrm{pH}$ gives favorable conditions to bacteria to grow faster [50].

Mutans streptococci (MS) are the main reason for developing dental cavities. To measure the effect of different snacks on the $\mathrm{pH}$ of plaque in school-going children, the study was conducted. The children were select with divergent levels of bacteria. Participants were six in number with a low level of bacteria in saliva (106 MS/ml). After giving different snacks results shows that these snacks lower the plaque $\mathrm{pH}$, which ultimately promotes dental caries. Researchers ranked the snacks as $10 \%$ sucrose $>$ milk chocolate $>$ sweet biscuit $>$ sticky rice with banana $>$ instant noodle [51]

\section{Symptoms of dental caries}

The fundamental reasons for dental cavities are sweeteners and high carbohydrates foods. Sucrose when matured by buccal cavity microbes like Lactobacillus casei and Streptococcus mutans gives high vitality esteems and hydrogen particle focus subsequently bringing down the $\mathrm{pH}$ which assimilates dentin and finishes prompting dental caries and promoting the demineralization of teeth. Kids who gulp down more soft drinks as compared to organic fruit juices and milk have more possibilities of growth of oral cavities. In school going children, more carbohydratecontaining snack consumption enhances the chance of oral cavities but cheese and yogurt intake after with cariogenic foods lowers the chance of cavities due to the presence of calcium, phosphorus, and buffering potential [52]. In the matter of fruits, the cariogenic potential index (CPI) of banana and kiwi is higher than any fruit. Sugar's dietary forms like honey, corn syrup, brown sugar produce organic acids by bacteria to cause cavities. The relation of sucrose with oral cavities has been accepted [53]. The critical $\mathrm{pH}$ varies over a broad range, its value relies on the concentrations of calcium and phosphate in the solution (Dawes, 2003). The most persistent symptoms related to oral caries were toothache $(56.2 \%)$, pain during eating or drinking (51.2\%), tooth sensitivity $(53.8 \%)$ and they related to socioeconomic status (SES). Pus in tooth and loose or separating teeth are related to low SES but bleeding during brushing of teeth, flossing, the sensation of the hot and cold count was higher in SES [54].

\section{Dental caries and saliva}

The process of Dental caries called an endemic bacterial ailment process, which caused by acids from bacterial assimilation diffusing into complete and dissolving the mineral. With the help of fermentable starches, micro-organisms make regular acids to destroy the teeth. The caries method is a continuum happening as a result of various cycles of demineralization and remineralization. Demineralization begins at the atomic level at the jeweled surface inside the clean. The major aim of the study was to analyze the physio-chemical properties of saliva that may include the flow of saliva, flow rate, $\mathrm{pH}$ calcium level, total protein, buffering capacity, anti-oxidant level among the caries-free children and the children with children having active caries [55]. A sample of 120 healthy children was taken and then divided into groups and further divided according to gender, then further divide into caries-free or 15 specific children with active caries in each group. A sample of unstimulated saliva was taken by the method of suction and then flow rates were used to determine. Then these samples were passed through a process to analyze the $\mathrm{pH}$, buffering capacity, protein, antioxidants, and calcium levels, then it passed through statistical analysis that includes t-test. The results reported that when a comparison analysis was taken among caries-free and 
active children flow rate, $\mathrm{pH}$ and buffering capacity were slightly reduced among caries active children but the content of protein and antioxidant has been increased among children with active children and the level of calcium has been decreased among caries active children a conclusion was drawn that the physicochemical properties of saliva play a significant role in the progression of saliva [56].

\section{pH and other factors in dental caries}

Some factors like salivary flow rate, buffering capacity, $\mathrm{pH}$ is highly related to oral health problems like dental caries, but some studies from the literature regarding cystic fibrosis associated with factors of salivary and some issues regarding caries are indeterminate. The purpose of this study was to analyze the effect of these factors and their relation to dental problems like caries among individuals who are suffering from cystic fibrosis. A sample of the un-stimulated whole was withdrawn from Seattle children hospital cystic fibrosis clinic $(n=83)$ from individuals ages falls from 6-20 years. The salivary flow rate was measure by unit ML per minute [58]. It can be measured by an instrument called laboratory $\mathrm{pH}$ meter. The capacity of buffering was measure by the titration with HCL. The resulting measurement includes the prevalence of caries; it may report the number of destructions among teeth that may include decaying of teeth, missing teeth, or fill primary and permanent tooth surfaces [59].

Thet-test and Spearman's rank correlation coefficient was used to test for the bivariate subordinate. The different kind of variable models like multiple variable regression model was used to perform a different kind of analyses that are confounder adjusted analyses or another method include the access of potential interactions. There was no relation among the prevalence of caries because of buffering capacity and salivary flow rate. There was a negative relation between the salivary $\mathrm{pH}$ and the prevalence of caries, but this relationship was no longer important after the age adjustment. There was no inclusive interaction among the salivary flow rate or the usage of antibiotics, buffering capacity, and some other factors of the salivary flow rate. The results reported that the unstimulated salivary factors are not associated with any oral health issues among the individuals having cystic fibrosis [60-65]. Dental caries in children and teenagers Sample of 630 parents and counseling of taking interest in their child's oral care was done by nutritionists and physicians in the Netherland show positive results as $80 \%$ of parents were convince and they pay attention to oral health to avoid dental cavities and tooth loss of their children [66-68]. The study included 7079 people, ages around about between 18-70 years. Study shows that $61.1 \%$ people have adequate oral care in childhood but rest of $38.9 \%$ people do not have proper and adequate oral care in their childhood which increases the risk of cavities and other diseases like periodontal diseases or oral cancer in their later ages [69-73]. Developmental defects of enamel in Chinese preschooler children can cause dental caries but consuming high sugary foods can make them even worse which gives the result of tooth loss [74-79].

To check the changes in salivary $\mathrm{pH} 39$ children aged 8-12 were evaluated. Saliva was collected after different intervals to know about changes in $\mathrm{pH}[80]$. The first-day carbonated drink was given and second-day fruit juice was given in non-transparent glass and then measure the $\mathrm{pH}$ changes by taking saliva immediately after the last sip, 5 minutes, 10 minutes after the last sip, 15 minutes after last sip and 30 minutes after the last sip [81]. And the results show that salivary $\mathrm{pH}$ was more lowered by mixed juice when differentiating with carbonated drinks [82]. According to collected data $\mathrm{pH}$ of saliva immediately goes to acidic medium after the 
last sip of juice. Data shows that $\mathrm{pH}$ ranges for mixed juice were lye between 3.26- 6.53 and their mean value was $4.89 \pm 0.97$ and for soda drinks, $\mathrm{pH}$ ranges lye from 3.21-6.86 and their mean values were $5.47 \pm 0.78$. Then it was concluded that both types of drinks lowered the salivary $\mathrm{pH}$ and they can cause tooth loss in severe damage. It was suggested not to drink these drinks daily [83].

The research was conduct between 90 school going children age 6-12. Children were divided into two groups study group and control group. Comparison between xylitolbased chewing gum and paraffin pellets and their effect on salivary $\mathrm{pH}$, the capacity of buffering, Streptococcus mutans level at baseline, and flow rate of saliva. Chewing gums were giving to them after their lunch in school. Data collected in two phases, in first phase data was collected with paraffin pellets and in second phase data was collected with xylitol-based chewing gum. After the evaluation of collected data, the results told after using stat-Graphics was that less $0.5 \%$ was affected on $\mathrm{pH}$ and buffering level. Less production of Streptococcus mutans was seen. But it shows to increase the production of saliva with increase salivary flow [84].

The study was conducted to evaluate the influence of behavioral peril feature and diet. The study consists of 782 teenagers between 11-17 years. The teenager was designated from public or government schools. All the members of the study were cross-examined with the help of a questionnaire. The questionnaire contains questions about their dietary habits, early morning habits, habits of tooth brushing, Food frequency chat. The criteria of formulation of form and its evaluation were according to the criteria of WHO. Teenager who consumes sugar tea, sugar milk, and biscuits once in a week increases the DMFT index. Those adolescents who brush their teeth less than 23 times a day have greater chances of developing dental caries. The study shows that the style of the utilization of sweetened food commodities has a great effect on plaque formation [85].

\section{Dental cavities}

Dental cavities not only considered as a medical problem, but numerous sociodemographic components are analogous with this. Several possibilities like eating, age, ethnic group, and gender, these factors play an important role in pervasiveness and incidence of dental cavities in population. Furthermore, factors that take part in causing the dental caries are the number of family members, the status of socio-economic, earnings or salary of parents and habits of oral sterility include perennial of brushing of the tooth in a day, mouth rinsing after eating, bad or faulty breath, toothache. Numerous studies organize in divergent urban and rural areas of India with great population report that as the age grows the number of chances of the ubiquity of dental cavities also increases. Children of low income or salary categories have increased the probability of success of oral cavities as compared to those children who belong to higher class families. Populations to lower or middle-class families usually have a lack of oral sanitation implementations as their living territory is unhygienic. These considerations frequently escort oral cavities. In the past usually, the regularity of oral cavities was evaluated by the number of siblings and family members. It was noted that if families have the only child have fewer chances of having dental caries as juxtapose to those families having two or more children. As the times pass and the number of family members increases, the lack of supervision and control are given by the mother given to them and the elder sibling receives most less care [32].

After dental caries, periodontal disease is the most leading disease of oral health. Its influence can be on more than one part of periodontium which appends alveolar bone, ligament of periodontal, cementum, and 
gingiva. It acts as a chronic disease and due to the high prevalence of the periodontal disease, it acts as a growing load on healthcare structure, people, and different societies around worldwide. In severe condition, periodontal disease leads to tooth loss and constitute to partial and full edentulism in the adult population with 5$20 \%$ globally. The treatment of periodontal disease is costly due to its prevalence and its rate of affection on the status of life. Studies show the evidence that periodontal disease can cause pain, discomfort, bleeding in the gingival layer, swelling, and food packing. This can be caused by gender, race, age, and area of residence of an individual to some severity and some variable extent. Plaque is the main reason for the occurrence of periodontal sickness. Plaque consists of those micro-organisms which lead to tooth loss in severe condition. These micro-organisms releases in two ways, directly and indirectly. Directly they release by enzymes, toxic products made during metabolism, and many other toxins. Indirectly it is released by the reaction of hypersensitivity and complement activation which leads to periodontal diseases. The main and only cause of periodontal disease is the disturbance of the balance of connection of etiological agents and resistance providers [33].

Cavities in primary dentition at less than 6 years of life called early childhood caries (ECC). It is multiplex and multifactorial disease, in which diseases are caused by different other diseases and also affect other diseases. It may cause by lack of education of parents, childhood indigence, unsuitable implementation of practices of feeding to the infant, lack of oral health beneficial nutrients, no or very fewer visits to the dentist, insufficient oral health care guidance, less perinatal fitness and other risk factors like microbiological and salivary factors promote the etiology of early childhood caries (ECC) [34].
Dental caries is $100 \%$ analogously with juices of fruit, but the connection between them is not yet clear. Children aged 2 to 10 years involved in National Health and Nutrition and their data were collected. After 14 surveys of National Health and Nutrition on children, researchers recommended that children who consume $100 \%$ organic juice at the amount of 17 ounces daily have increased the feasibility for micro-organisms to grow and cause dental caries [35].

\section{Dental caries and genes}

Genes have a special place in human life. Many diseases depend on the genetic making of a person. Twin studies and heritability takes a major part in causing dental caries. There are two types of dentations, primary dentition, and permanent dentition. Phenotype variations with 50-70\% take place in the prevalence of primary dentition while in permanent dentition it takes 35-55\% [90]. Many genes necessitate the development and formation of the tooth, salivary protein, and immunological system.

The study was conducted to estimate the link between dental cavities and sweet genes. Researchers investigate the intake of sugar and liking sweet products daily. As individuals like to eat sweet products daily, it can increase the chance of dental caries. Research involves the measurements of missing teeth, decayed teeth, filled teeth, and DMFT index. 362 females and 285 males between 18-65 years participate in the study. Participants were select from six different villages of northeastern Italy. Liking sweet food products was evaluated with the help of a 9-point scale [91]. Dietary history taken from participants to calculate the daily consumption of simple sugar; it includes both naturally found sugar in food and artificially added sugar food products. Two genes that are associated with the DFMT index are GLUT2 and TAS1R2. A comparison of both GG homozygous individuals for rs 1499821 in GLUT2 gene and rs3935570 in the 
TAS1R2 gene was calculated. This shows that GLUT2 shows a higher level of DMFT with $p$-value 0.0273 while TAS1R 2 shows a $p$-value 0.0117 . This study reveals that there is a great factor of genes in causing cavities pervasiveness and accentuate the character of liking the sweet products as it indicates the risk of dental caries [92].

\section{Importance of nutrition in dental caries}

According to the American diet association that nutrition is an essential component for the maintenance of oral health. The American Dietetic Association (ADA) influences the compounding of oral health with other services like nutrition services, education, and research. Dietetics and dental professionals collaborated for the maintenance of oral health and it is highly recommended for the prevention of intervention of oral health. The epidemiological and scientific data propose a womb to tomb collaboration among nutrition and the maintenance of oral health or prevention of disease. The relation of oral health and nutrition had an interactive duplex relationship. The functional ability to diet and nutritional status was affected by oral health and some oral infections like a chronic, acute, terminal systemic disease with oral infection signs and symptoms impacted the functional ability to eat diet and nutrition may impact the progression of the oral cavity and oral health diseases. As the acknowledgment enhanced or more discoveries show the link between oral and nutritional health. The health care providers of both disciplines have to know about the screening, or some important baseline education or the inclusively the patient care. The practice of dietetics requires registered dietitians that must provide medical nutrition therapy that inclusively incorporates a patient requirement that includes all the aspects of oral health and or the other bodily need as well. A perspective was concluding by the dietetic and the other clinical practices that intimate that the nutrition in oral health is necessary and essential for oral health and dietetic educational awareness programs. In research, education the collaboration between dietetics and dentistry is required for oral health betterment, and the depiction of health provider practice roles is needed to guarantee intensive health care [40].

\section{Fruits and oral health}

Fruit considered as healthy food commodity as it contains a large number of vitamins and minerals which helps in all processes taken place in the body. The fruit was a healthy choice and recommended daily as 2-3 serving daily for normal individuals [61]. A healthy diet contains fruit juice daily as they play an important role in the functioning of the body. One cup of fruit juice provides different nutrients like potassium, vitamin $\mathrm{C}$, folate, phosphorus, and antioxidants. Australian Guide to Healthy states that "Fruit juice should count as serving in daily diet plan". Fruit juices fortified with calcium, fiber, vitamin A promoted for good health and it helps in enhancing the nutritional contribution in a healthy diet [62].

\section{Dental health and carbohydrates}

Dental plaque $\mathrm{pH}$ changes, after the utilization of sweet chocolate, sweet cookies, instant noodles, sticky rice with banana, and a $10 \%$ sucrose positive control were estimated utilizing $\mathrm{pH}$-anode. The test foods were position by most extreme $\mathrm{pH}$ drop in about indistinguishable requests in the two gatherings from taking after $10 \%$ sucrose $>$ sweet chocolate $>$ sweet cookies $>$ sticky rice with banana $>$ instant noodle [63].

\section{Dental caries and calcium}

The addition of calcium salts in juices and other foods helps in fighting against $\mathrm{pH}$ lowering substances but the evaluation of calcium-fortified products shows that they also promote the lowering of $\mathrm{pH}$ of saliva to some extent. After the consumption of calcium-fortified products, there was a drop 
in salivary $\mathrm{pH}(\mathrm{p} / 0.5)$ and a decrease in perceived taste (p/0.001) [64].

\section{Dental caries and cereals}

Many commercial brands declare that their breakfast cereals provide protein with other essential nutrients but flavored and unflavored cereals, both were cariogenic to oral health. Flavored cereals drop the maximum $\mathrm{pH}$ within 15 minutes while unflavored cereals take more time to drop the $\mathrm{pH}$ at the maximum level. In the comparison of carcinogenicity and microbiological effects of soluble starch and sucrose shows that sucrose is more cariogenic then soluble starch [65]. The value of $\mathrm{pH}$ goes down to 0.005 after 20 minutes of consumption of ready to eat dry cereals with sugar added which can cause caries in teeth. There was an immediate higher fall in salivary $\mathrm{pH}$ after consuming fresh fruit juices and it advised to swill the mouth after drinking fruit juice [66]. Exposure of carbohydrates for a long period can cause acidic plaque habitat for bacteria which can cause demineralization of the enamel of teeth and then at the end cavity is formed. Hydroalcoholic compounds of juice and peel of pomegranate show cariogenic properties but literature show that polyphenolic extracts of pomegranate used for the treatment and prevention of dental cavities [67].

Raisins contain flavonoids, iron, and polyphenols which had good potential to give health benefits. Examination of raisins and bran cereals containing raisins in children between 7-11 years shows that it does not lower the salivary $\mathrm{pH}$ under 6 in the next 30 minutes of consumption and it was considered as a healthy snack as compare to frequently eaten snack foods [68].

\section{Dental caries and drinks}

Drinks were wealthy in sugar and producers should better educate customers on the sugar content. Dental caries was a perpetual sickness of adolescence, which has normal hazard factors with weight. General experts, dieticians, and dental practitioners must cooperate to give preventive direction: natural product juice consumption should be limited and different refreshments restricted to incidental utilization; organic product juice may add to just a single segment of the suggested daily five servings [69]. Dentists, when talked about the oral disease with patients, should acknowledge about sugary and non-sugary foods and their possible effect on health but hydroxyapatite contains little amount of impurities such as sodium, carbonate magnesium, etc and these impurities promote the loss of phosphate and calcium when an acid attack the tooth [70]. Oral cavities formed when the frequency of consumption of acidic drinks increased to limits. The most consumed drink was orange juice and cola based drinks. Both drinks are acidic but their ability to sustain the low $\mathrm{pH}$ for a longer period was different due to buffering action of phosphoric acid in cola based drinks and it had low titratable acidity (maintaining low $\mathrm{pH}$ for time) but the oranges had high titrable acidity due to the presence of citric acid, naturally present in all citrus foods. All the citrus food had a high capacity to drop the salivary $\mathrm{pH}$ for a longer period and cause dental cavities [71].

Fresh fruit juices were considered as a beneficial and nutritious drink that provides lots of vitamins and minerals to the body but there are some side effects also present. Some fruits are acidic thus their juices are also acidic which helps in the growth of bacteria like Streptococcus mutans and Lactobacillus casei and cause cavities [72]. The range of $\mathrm{pH}$ drop after consumption of different juices were 3.12- 6.01 and a major fall in $\mathrm{pH}$ level after drinking mixed fruit juice. There was an immediate higher fall in salivary $\mathrm{pH}$ after consuming fresh fruit juices and is advised to swill the mouth after drinking fruit juice [73]. Research on 723 subjects with proper and complete data, contains $54 \%$ females, and $46 \%$ of males show that there is a $33 \%$ 
prevalence of caries. Mostly people consumed sugar drinks and highly refined carbohydrates but after modification in their diet shows better results and decrease in dental caries. Modification of diet contains the replacement of sugary drinks to natural juices without added sugar and refined carbohydrate to unrefined carbohydrates which consist of high fiber as compared to refined [74].

The $\mathrm{pH}$ of saliva immediately drops down after the consumption of sugary rich drinks. As they explicated from mouth rapidly, they had erosive and cariogenic property which promote the lowering of $\mathrm{pH}$ of saliva and cause dental cavities. Then it was suggested minimizing the consumption of sugary rich drinks, especially in children to prevent dental cavities [75].

Two properties of soda drinks are thought to be the reason of carcinogenicity, first is its ability to cause lowering of $\mathrm{pH}$ and some drinks have the ability of titrable acidity which causes damage and erosion on surfaces of enamel and second is soda drinks contain fermentable carbohydrates which are then metabolized with help of plaque and microorganism and they make organic acids as their by-product in saliva and dental plaque. Then the process of demineralization leading toward oral cavities [76]. Fruit juices manufacturer add more sugar in their processing of juice because it enhances and increases the taste. More sugar more the taste. Carbonated drinks have more content of acidic which means it has more ability to lead towards the process of demineralization of enamel surface [77].

\section{Dental caries and probiotics}

Probiotics present in yogurt have many health benefits as it helps in digestion of foods and enhance the immunity of individual also helps in curing the dental cavities but further studies need to find out the relation between probiotics and oral health properly [78]. Encouragement of sleep and restrict rich sugary drinks and food provide several advantages like weight loss and prevention of dental caries [79].

\section{Dental caries and cheese}

According to Turkish heritage, their white cheese accommodates less protein, phosphate, and calcium when the cheese is juxtaposed with cheddar cheese, but it was unknown to find its potential of causing carcinogenicity. In turkey, sugarless yogurt and white cheese are persistently devoured in breakfast daily. The study was conducted to appraise the acidogenic prospects of white cheese and sugarless yogurt with a drench of tincture of sucrose. After consumption $\mathrm{pH}$ microelectrode was used to measure the $\mathrm{pH}$ of plaque at different intervals between 1-60 minutes. White cheese seems to raise the $\mathrm{pH}$ after 1 minute of the utilization of the sample. Utilization of white cheese for 5 minutes after drench of $10 \%$ tincture of sucrose raises the $\mathrm{pH}$ level rapidly but consumption of sugarless yogurt for 5 minutes after sucrose solution knock down the $\mathrm{pH}$ level as before utilization. The study shows that sugarless yogurt reduces the $\mathrm{pH}$ level while white cheese increases the $\mathrm{pH}$ level of plaque [86].

\section{Dental caries and chewing}

In the 1970s, chewing gum was firstly used in the dentistry department to check their relationship with each other. A study was conduct called Turku sugar studies during the years 1973-1973 and results show excellent work on xylitol-based chewing gums as super anti-caries qualities. After successful results, many doctors especially Scandinavian countries-based dentists start studying on prevention of dental caries with the help of the importance of masticating the xylitol based sweetened gums [87]. According to the research amount of saliva production is equal to the amount of presence of dental caries. Chewing gums are known to increase and promote more production of saliva. The research was conduct and after different clinical trials show that if an individual 
consumes sugar-free chewing gum after meals for some time it helps in diminishing the occurrence of dental cavities [88].

The research was conducted on chewing gum between 45 school-going children. Children were divided into two groups study group and control group. Comparison between xylitolbased chewing gum and paraffin pellets and their effect on salivary $\mathrm{pH}$, the capacity of buffering, Streptococcus mutans level at baseline, and flow rate of saliva. Chewing gums were giving to them after their lunch in school. Data collected in two phases, in first phase data was collected with paraffin pellets and in second phase data was collected with xylitol-based chewing gum. After the evaluation of collected data, the results told after using stat-Graphics was that less $0.5 \%$ was affected on $\mathrm{pH}$ and buffering level. Less production of Streptococcus mutans was seen. But it shows to increase the production of saliva with increase salivary flow [89].

\section{Dental caries and bread}

Different type of bread was used all over the world according to consumers taste and preferences. Bread is considering a rich source of energy as it contains lots of carbohydrates. Two types of bread are used consist of dissimilar physical attributes, simple traditionally baked, and second was soft and bulky bread. The participant was select based on DMFT. The bread was given to participants after the $\mathrm{pH}$ of the plaque was tested after different interregnum followed by right after last bite, 1 minute, 5 minutes, 10 minutes, 15 minutes, 20 minutes, 30 minutes. ANOVA and Tukey test $(\alpha=0.05)$ was used for the examination of data. The result shows that soft and bulky bread can cause more dental caries as compared to simple baked bread [93].

\section{Dental caries and chocolates}

A study was conducted to analyze the acidogenic response of plaque while using different European chocolates with different concentrations of cocoa powder.in this study,
14 subjects were selected to investigate the response.in In this, the plaque test was conducted at baseline level at different time intervals as $2,5,10,15,20$, and 30 minutes after the consumption of comparative foods including test chocolate or control foods. In the 30 secs, a sample of the plaque was abstracted from the buccal area of the posterior side of teeth that represent half of the teeth portion. the instrument used to measured the plaque was the ISFET electrode that had been connected to the Sentron 2001 ph system [94]. Different variety of chocolates were selected with different content of coca ratios, the test chocolates were diet chocolate, plain English chocolate, plain European chocolate, milk English chocolate, milk European chocolate, milk chocolate with hazelnuts and white chocolates having different cocoa content respectively $34,70,20,30,20 \%$ and no cocoa.the were allowed to consume $15 \mathrm{~g}$ of each chocolate and the adequate amount of sucrose and sorbitol solution was presented to the volunteers as a control food that was about $10 \%$. then the results analyzed the diet chocolates gave significantly different results as compared to other chocolates or and similar to the parameters that were studied for the solution of sorbitol. The PEC and MHC showed $\mathrm{pH}$ that ranges that were lower at $0.20 \pm 0.34$ and $0.60 \pm 1.40$ they are lower than critical ph that was 5.7, while on the comparison to the sucrose solutions the mean values were $1.38 \pm 1.03$ these were not statically evidentiary. The acidogenic potential of chocolates was analyzed and here the values of all the chocolates and solutions, the API of DC was about AB 0.03, PEC approximately 0.41, PEnC that was about 0.66 , MEnc gave 0.93 and the other gave the ranges of 0.88 and 0.45 , the sucrose solution gives about 1.00 API. A summary was that the diet chocolates have no acidogenic effect [95]. 


\section{Conclusion and recommendations}

It shows that the simple fruit lowers less $\mathrm{pH}$ of saliva as juxtapose to processed juices due to presences of artificial sugars. Simple fruit contains more nutrients than juices. But fresh juice contains nutrients that accept fiber content and less deduction of other nutrients than in processed juice. Fresh juices between processed juice and simple fruit because it lowers the $\mathrm{pH}$ not so down to cause destruction. Most $\mathrm{pH}$ was lower by processed juice. Daily consumption of processed juice can cause dental caries which lead to loss of teeth in later ages. Oral health is most important for the rest of the body; any oral diseases can lead to many other diseases in the body.

- Effect of carcinogenicity of snacks in school-going children.

- Demineralization potential of different concentrations of different beverages.

- Alternative means to reduce the acidogenic potential of juices.

- Relation of different types of sugars with dental caries in older people.

- Carcinogenicity of cooked and uncooked vegetables, which are economically present in Pakistan.

- Effect of fresh fruits on salivary $\mathrm{pH}$ according to their glycemic index (GI).

\section{Authors' contributions}

Conceived the idea: N Zafar \& A Ali, Corrections: S Imtiaz, A Zafar \& MY Afzal, Proof Reading: F Mazhar, M Sarwar \& U Nazir, Correspondence: N Zafar, Wrote the Paper: N Zafar, S Siddiq, S Ghafar \& M Sikandar.

\section{References}

1. Touger-Decker R \& Mobley CC (2007) American Dietetic Association: Position of the American Dietetic Association: oral health and nutrition. J Am Diet Assoc 107: 1418-28.

2. Vanobbergen J, Martens L, Lesaffre E, Bogaerts K \& Declerck D (2001). Assessing risk indicators for dental caries in the Primary Dentition. Community Dent Oral Epidemiol 29: 424-34

3. Oliveira BH, Salazar M, Carvalho DM, Falcão A, Campos K \& Nadanovsky P (2014). Biannual fluoride varnish applications and caries incidence in preschoolers: A 24-month follow-up randomized placebo-controlled clinical trial. Caries Res 48: 228-36.

4. Beil H, Rozier RG, Preisser JS, Stearns SC \& Lee JY (2014). Effects of early dental office visits on dental caries experience. Am J Public Health 104: 1979-85.

5. Prabhakar A, Dodawad R \& Os R (2009). Evaluation of flow rate, $\mathrm{pH}$, buffering capacity, calcium, total protein, and total antioxidant levels of saliva in caries-free and caries active children-an in vivo study. Int $\mathrm{J}$ Clin Paediatr Dent 2: 9-12.

6. Montero J, Costa J, Bica I, \& Barrios R (2018). Caries and quality of life in Portuguese adolescents: Impact of diet and behavioral risk factors. J Clin Experi Dent 2: 54-61.

7. Faustova MO, Ananieva MM, Basarab YO, Dobrobolska OV, Vovk IM \& Loban GA (2018). Bacterial factors of cariogenicity (literature review). Wiad Lek 71: 378-382.

8. Paglia L, Scaglioni S, Torchia V, De Cosmi V, Moretti M, Marzo G \& Giuca R (2016) Familial and Dietary Risk Factors in Early Childhood Caries. Eur J Paedtr Dent 17: 93-99.

9. Thaweboon S, Suddhasthira T, Thaweboon B, Soo-Ampon S \& Dechkunakorn S (2007). Plaque pH response to snack foods in children with different levels of mutans streptococci. South Asian J Trop Med Public Health 38: 598-603.

10. Mafla AC, Villalobos-Galvis FH \& Heft MW (2018). Illness perceptions 
amongst individuals with dental caries. Com Dent Health 35: 16-22.

11. Wu CD (2009). Grape Products and Oral Health. J Nutri 139: 1818S-1823S.

12. Sezgin BI, Onur ŞG, Menteş A, Okutan AE, Haznedaroğlu E \& Vieira AR (2018). Two-fold excess of fluoride in the drinking water has no obvious health effects other than dental fluorosis. $J$ Trace Elem Med Biol 50:216-222.

13. Grag B, Sanjay C, Taranjot K, Deepika K \& Deepanshu G (2016). Effect of Consumption of Different Fruit Juices on Salivary Ph. Int J Cont Med Re 3: 28002802

14. Landon S (2013). Fruit juice nutrition and health. Food Aus 59: 533-538.

15. Sardana V, Balappanavar AY \& Patil GB (2012). Impact of a modified carbonated beverage on human dental plaque and salivary $\mathrm{pH}$ : an in vivo study. J Indian Soc Pedod Prev Dent30: 7-12.

16. Franklin S, Masih S \& Thomas AM (2015). Effect on oral $\mathrm{pH}$ changes and taste perception in 10-14-year-old children, after calcium fortification of a fruit juice. Eur Arch Paed Dent 16: 483489.

17. Abdul M, Katari S, Chunawalla Y, Talathi R, Batra J \& Singh H (2014). Cariogenicity of Breakfast Cereals. Oral Hyg Health 2: 161.

18. Thurnheer E, Giertsen R, Gmu“r \& Guggenheim B (2008). Cariogenicity of soluble starch in oral in vitro biofilm and experimental rat caries studies: a comparison. J Appl Micro 105: 829-836.

19. Torbjörn S, Gunnar G Dahlén \& Ove S Wattle (2007). Caries in the infundibulum of the second upper premolar tooth in the horse. Acta Vet Sca 49: 10-23.

20. Shetgar Sp, Umesh K, Sangeeta C \& Rahul P (2017). Effect of Fresh Fruit Juices on Salivary pH: A Randomized
Controlled Trial. Int J O Health Med Re 3: 28-32.

21. Mahesh J, Sapna B, Veeresh DJ \& Divya D (2016). Comparative evaluation of change in salivary ph on the consumption of dry ready to eat cereals, cereals with and without added sugar in milk- an in-vivo study. IJMRPS 3: 2732.

22. Marsh (2010). Sugar, fluoride, pH, and microbial homeostasis in dental plaque. Proc Finnish Dent Soc 87: 515-525.

23. Ferrazzano GF, Elisa S, Daniela S, Gabiria P, Roberta C, Chiara P, Tiziana C, Brunella A, Marco C, Aniello, Elena S, Annunziata GC, Maria GV, Michele DS \& Paola S (2017). In Vitro Antibacterial Activity of Pomegranate Juice and Peel Extracts on Cariogenic Bacteria. BioMed Re Int 2: 1-7.

24. Montoya JAG, Ramon JM, GonzalezMoles MA (2018). Oral Health-Related Quality of Life and Nutritional Status. $J$ Public health Dent 68: 88-93.

25. Catteau C, Trentesaux T, Delfosse C \& Rousset MM (2012). Consumption of fruit juices and fruit drinks: impact on the health of children and teenagers, the dentist's point of view. Arch Pediatr 19: 118-24

26. Naval S, Koerber A, Salzmann L, Punwani I, Johnson BR \& Wu CD (2013). The effects of beverages on plaque acidogenicity after a sugary challenge. J Am Dent Assoc 144:815-22.

27. Lussi A, Jaeggi $\mathrm{T} \&$ Jaeggi-Schärer $\mathrm{S}$ (2011). Prediction of the erosive potential of some beverages. Caries Res 29: $349-54$

28. Asmyhr O, Grytten J \& Holst D (2012). Occurrence of risk factors for dental erosion in the population of young adults in Norway. Com Dent Oral Epide 40: 425-31.

29. Tenuta L MA, Fernadez CE, Brando ACS \& Cury JA (2015). Titratable 
acidity of beverages influences salivary pH recovery. Braz Oral Re 29: 1-6.

30. Kempara J, Lu G, Tiansong Xu, Gang H, Song J, Yan G \& Feng C (2017). Oral microbiomes: more and more important in the oral cavity and the whole body. Pro Cell 9: 488-500.

31. World Health Organization, Oral health information sheet, 2008.

32. Hans R, Thomas S, Garla B, Dagli RJ \& Hans MK (2016). Effect of Various Sugary Beverages on Salivary $\mathrm{pH}$, Flow Rate, and Oral Clearance Rate amongst Adults. Scientifica (Cairo) 50: 502-523.

33. Grenby TH, Mistry M \& Desai T (2009). Potential dental effects of infants' fruit drinks studied in vitro. Br J Nutr 64: 273 83.

34. Grobler SR, Jenkins GN \& Kotz D (2015). The effect of consumption and method of drinking. Br Dent J 158: 2936.

35. Birkhed D (2014). Sugar Content, Acidity, and effect on plaque $\mathrm{pH}$ of fruit juices, fruit drinks, carbonated beverages, and sports drinks. Caries Res 18: 120-27.

36. Pradeep K, Kuttappa MA \& Prasana KR (2014). Probiotics and oral health: an update. SADJ 69: 20-4.

37. Arvidsson L, Birkhed D, Hunsberger M, Lanfer A, Lissner L, Mehlig K, Mårild S \& Eiben G (2016). BMI, eating habits, and sleep in relation to salivary counts of mutans streptococci in children - the IDEFICS Sweden study. Public Health Nutr 19: 1088-1092.

38. Berendsen J, Bonifacio C, van GemertSchriks M, van Loveren C, Verrips E \& Duijster D (2018). Parents' willingness to invest in their children's oral health. $J$ Public Health Dent 78: 69-77.

39. Crouch E, Radcliff E, Nelson J, Strompolis M \& Martin A (2018). The experience of adverse childhood experiences and dental care in childhood. Com Dent Oral Epide 46: 442-448.

40. Li Y, Chen X, Chen S, Janal MN \& Sarnat H (2018). Developmental defects of enamel increase caries susceptibility in Chinese preschool children. Com Dent Oral Epide 46: 500-510.

41. Isha G, Navit S, Sandeep SM, Mandeep R, Pragati N \& Sneha C (2013). Effects of Carbonated Drink \& Fruit Juice on Salivary $\mathrm{pH}$ of Children: An in Vivo Study. Int J Sci Study 01: 60-69.

42. Ribelles Llop M, Guinot Jimeno F, Mayné Acién R, \& Bellet Dalmau LJ (2010). Effects of xylitol chewing gum on salivary flow rate, $\mathrm{pH}$, buffering capacity, and presence of Streptococcus mutans in saliva. Eur $J$ Paediatr Dent 11: 9-14.

43. Montero J, Costa J, Bica I \& Barrios R (2018). Caries and quality of life in Portuguese adolescents: Impact of diet and behavioral risk factors. J Clin Experi Dent 2: 54-61.

44. Şaroğlu SI \& Aras Ş (2007). Effect of White Cheese and Sugarless Yoghurt on Dental Plaque Acidogenicity. Cari Res 41: 208-211.

45. Stookey GK. 2008. The effect of saliva on dental caries. J Am Dent Assoc 139: $11 \mathrm{~S}-17 \mathrm{~S}$.

46. World Health Organization, Oral health information sheet, 2012.

47. Wang X, Shaffer JR, Zeng Z, Begum F, Hu FB, Vieira AR, Noel J, Anjomshoaa I, Cuenco KT, Lee MK, Beck J, Boerwinkle E, Comelis MC, Crosslin DR, Laurie CC, Nelson SC, Doheny KFF, Pugh EW, Polk DE, Weyant RJ, Crout R, McNeil DW, Weeks DE, Feingold E \& Marazita ML (2012). Genome-wide association scan of dental caries in the permanent dentition. $B M C$ Oral Health 12: 57.

48. Wendell S, Wang X, Brown M, Cooper ME, DeSensi RS, Weyant RJ, Crout R, 
McNeil DW \& Marazita ML (2010). Taste genes associated with dental caries. J Dent Res 89: 1198-1202.

49. Slayton RL, Cooper ME, Maraita ML (2005). Tuftelin, mutant streptococci, and dental caries susceptibility. J Dent Res 84: 711-719.

50. Deeley K, Letra A, Rose EK, Brandon CA, Resick JM, Marazita ML \& Vieira AR (2008). Possible association of amelogenin to high caries in a Guatemalan-Mayan population. Caries Res 42: 8-13.

51. Azevedo LF, Pecharki GD, Brancher JA, Corderio CA Jr, Medeiros KG, Antunes AA, Arruda ES, Wermeck RI, de Azevedo LR, Mazur RF, Moyses SJ, Moyses ST, Faucz FR \& Trevilatto PC (2010). Analysis of the association between lactotransferrin (LTF) gene polymorphism and dental caries. $J$ Appl Oral Sci 18: 166-170.

52. Kuchler EC, Deeley K, Ho B, Linkowski S, Meyer C, Noel J, Kouzbari MZ, Bezamat M, Granjeiro JM, Antunes LS, Antunes LA, de Abreu FV, Costa MC, Tannure PN, Seymen F, Koruyucu M, Patri A, Mereb JC, Poletta FA, Castilla EE, Orioli IM, Marazita ML \& Vieira AR (2013). Genetic mapping of high caries experience on human chromosome 13. BMC Med Genet 14: 116.

53. Robino A, Bevilacqua L, Pirastu N, Situlin R, Di Lenarda R, Gasparini P \& Navarra CO (2015). Polymorphisms in sweet taste genes (TAS1R2 and GLUT2), sweet liking, and dental caries prevalence in an adult Italian population. Genes \& Nut 10(5).

54. Shiva Mortazavi and Sogol Noin (2011). Plaque $\mathrm{pH}$ Changes Following Consumption of Two Types of Plain and Bulky Bread. Dental Res J 2: 80-82.

55. Verakaki E \& Duggal MS (2003). A comparison of different kinds of
European chocolates on human plaque pH. Eur J Paedtr Dent 4: 203-210.

56. Poulton R, Leonard A, Jonathan M \& Murry $\mathrm{T}$ (2012). Impact of dental visiting trajectory patterns on clinical oral health and oral health-related quality of life. J Pub Health Den 72: 36-44.

57. Gokul G, Vishnupriya V \& Gayathri R (2016). A study on variations of salivary ph with the intake of food. AJPCR 9: 13.

58. Boeing H, Bechthold A, Bub A, Jonas B \& Rubeb JH (2012). Critical review: vegetables and fruits in the prevention of chronic diseases. Eur J Nutr 51: 637663.

59. Crowe FL, Roddam AW \& Key TJ (2011). Fruit and vegetable intake and mortality from ischaemic heart disease: results from the European Prospective Investigation into Cancer and Nutrition (EPIC)-Heart study. Eur Heart $J$ 32: 1235-1243.

60. Azeredo FN, Guimarães LS, Luís W, Fialho S, Antunes LAA, \& Antunes LS (2020). Estimated prevalence of dental caries in athletes: An epidemiological systematic review and meta-analysis. Ind J Dent Res 31(2): 297.

61. Flood A, Velie EM \& Chaterjee N (2009). Fruit and vegetable intakes and the risk of colorectal cancer in breast cancer detection. Am J Clin Nutr 75: 936-943.

62. Moore LL, Singer MR \& Bradlee ML (2010). Intake of fruits, vegetables, and dairy products in early childhood and subsequent blood pressure change. Epidemiol 16: 4-11.

63. Ruel G, Shi Z, Zhen S, Zuo H, Kröger E, Sirois C \& Taylor AW (2014). Association between nutrition and the evolution of multimorbidity: The importance of fruits and vegetables and whole-grain products. Clin Nutri 33: 513-520. 
64. Gokul G, Vishnupriya V \& Gayathri R (2016). A study on variations of salivary ph with the intake of food. AJPCR 9: 13.

65. Moynihan P (2005). The interrelationship between diet and oral health. Proc Nutr So 64: 571-580.

66. Lacopino AM (2006). Maintaining oral health in the aging population: the importance of the periodontal-systemic connection in the elderly. Grand Rounds Oral-Sys Med 3: 25-37.

67. Landon S (2013). Fruit juice nutrition and health. Food Aus 59:533-538.

68. Ritchie CS, Joshipura K, Hung HC \& Douglass CW (2002). Nutrition as a mediator in the relation between oral and systemic disease: Associations between specific measures of adult oral health and nutrition outcomes. Crit Rev Oral Biol Med 13: 291-300

69. Batra P, Saini P, \& Yadav V (2020). Oral health concerns in India. J Oral Biol Craniofac Res

70. Mangan DF (2002). Nutrition and oral infectious diseases: Connections and future research. Compend Cont Educ Dent 23: 416-422.

71. Scardina GA \& Messina P (2012). Good Oral Health and Diet. $J$ of Biol Biotechnol 3: 8-12.

72. Petersen PE and Ogawa H. 2005. Strengthening the prevention of periodontal disease: The WHO approach. J Periodontol 76: 2187-93

73. Gokul G, Vishnupriya V \& Gayathri R (2016). A study on variations of salivary ph with an intake of food. AJPCR 9: 1-3.

74. Coleman AL, Stone KL, Kodjebacheva G, Elli G, droil FS \& Aqsr H (2008). Glaucoma risk and the consumption of fruits and vegetables among older women in the study of osteoporotic fractures. Am J Ophthalmol 145:10811089.
75. Ruel G, Shi Z, Zhen S, Zuo H, Kröger E, Sirois C \& Taylor AW (2014). Association between nutrition and the evolution of multimorbidity: The importance of fruits and vegetables and whole-grain products. Clin Nutri 33: 513-520.

76. Moynihan P (2005). The interrelationship between diet and oral health. Proc Nutr So 64: 571-580.

77. Tahmassebi JF, \& BaniHani A (2020). Impact of soft drinks to health and economy: A critical review. Eur Arch Paediatr Dent 21(1): 109-117.

78. Shen A, Bernabé E, \& Sabbah W (2020). Severe dental caries is associated with the incidence of thinness and overweight among preschool Chinese children. Acta Odontol Scand 78(3): 203-209.

79. Mangan DF (2002). Nutrition and oral infectious diseases: Connections and future research. Compend Cont Educ Dent 23: 416-422.

80. Cascaes AM, Bielemann RM, Clark VL \& Barros AJ (2014). Effectiveness of motivational interviewing at improving oral health: a systematic review. Rev Saude Public 48: 142-153.

81. Marshall TA, Lim S, Sohn W, Burt BA, Sandretto AM, Kolker JL \& Ismail AI (2013). Cariogenicity of soft drinks, milk, and fruit juice in low-income African-American children: a longitudinal study. J Am Dent Assoc 139: 959-967.

82. Liliya D, Peter B \& Milena P (2015). Assessment of food habits in children aged 6-12 years and the risk of caries. Biol Biotechnol 29: 200-204.

83. Rego IN, Cohen-Carneiro F, Vettore MV, Herkrath FJ, Herkrath APCDQ, \& Rebelo MAB (2020). The association between nutritional status and dental caries in low-income children: A multilevel analysis. Int J Paedtr Dent 
84. Arvidsson L, Birkhed D, Hunsberger M, Lanfer A, Lissner L, Mehlig K, Mårild S \& Eiben G (2016). BMI, eating habits, and sleep in relation to salivary counts of mutans streptococci in children - the IDEFICS Sweden study. Public Health Nutr 19:1088-92.

85. Berkowitz RJ (2003). Acquisition and transmission of mutans streptococci. $J$ Calif Dent Assoc 31: 135-8.

86. Bernabé E \& Sheiham A (2014). Tooth loss in the United Kingdom--trends in social inequalities: an age-period-andcohort analysis. PLoS One 9: 23-28.

87. Cassolato SF \& Turnbull RS (2003). Xerostomia: clinical aspects and treatment. Gerodontol 20: 64-77.

88. Chankanka O, Katri G, Barose M \& Miama H (2011). Mixed dentition cavitated caries incidence and dietary intake frequencies. Ped Dent 33: 233 243.

89. Dawes C (2003). What is the critical pH and why does a tooth dissolve in acid? $J$ Can Dent Assoc 69: 722-744.

90. Featherstone (2011). The Evidence for Caries Management by Risk Assessment. Adv Den Re 29: 678-682.
91. Humphrey SP \& Williamson RT (2001). A review of saliva: normal composition, flow, and function. J Prosthet Dent 85: 162-169.

92. Karshima SN (2018). Parasites of importance for human health on edible fruits and vegetables in Nigeria: a systematic review and meta-analysis of published data. Pathol Glo Health 112: 47-55.

93. Kolderman E, Bettampadi D, Samarian D, Dowd SE, Foxman B, Jakubovics NS \& Rickard AH (2015). L-Arginine Destabilizes Oral Multi-Species Biofilm Communities Developed in Human Saliva. PlOS One 10: 35-42.

94. Asmyhr O, Grytten J \& Holst D (2012). Occurrence of risk factors for dental erosion in the population of young adults in Norway. Com Dent Oral Epide 40: 425-31.

95. Klonoff CD (2009). The Beneficial Effects of a Paleolithic Diet on Type 2 Diabetes and Other Risk Factors for Cardiovascular Disease. J Dia Sci Tech 3: $1229-1232$. 